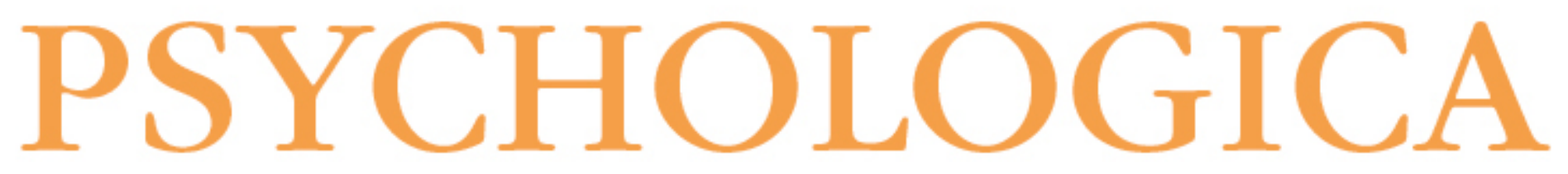

Segurar a família pelas pontas: os dilemas dos avós cuidadores a tempo inteiro

Autor(es): $\quad$ Jorge, Helena; Lind, Wolfgang

Publicado por: Imprensa da Universidade de Coimbra

URL

persistente: $\quad$ URI:http://hdl.handle.net/10316.2/38636

DOI: $\quad$ DOI:http://dx.doi.org/10.14195/1647-8606_58-1_1

Accessed : $\quad$ 26-Apr-2023 10:35:35

A navegação consulta e descarregamento dos títulos inseridos nas Bibliotecas Digitais UC Digitalis, UC Pombalina e UC Impactum, pressupõem a aceitação plena e sem reservas dos Termos e Condições de Uso destas Bibliotecas Digitais, disponíveis em https://digitalis.uc.pt/pt-pt/termos.

Conforme exposto nos referidos Termos e Condições de Uso, o descarregamento de títulos de acesso restrito requer uma licença válida de autorização devendo o utilizador aceder ao(s) documento(s) a partir de um endereço de IP da instituição detentora da supramencionada licença.

Ao utilizador é apenas permitido o descarregamento para uso pessoal, pelo que o emprego do(s) título(s) descarregado(s) para outro fim, designadamente comercial, carece de autorização do respetivo autor ou editor da obra.

Na medida em que todas as obras da UC Digitalis se encontram protegidas pelo Código do Direito de Autor e Direitos Conexos e demais legislação aplicável, toda a cópia, parcial ou total, deste documento, nos casos em que é legalmente admitida, deverá conter ou fazer-se acompanhar por este aviso. 


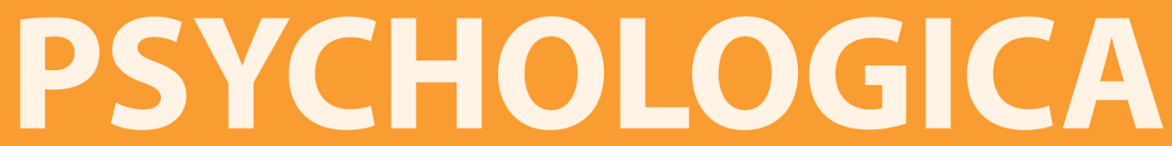

IMPRENSA DA UNIVERSIDADE DE COIMBRA COIMBRA UNIVERSITY PRESS

FACULDADE DE PSICOLOGIA E DE CIÊNCIAS

DA EDUCAÇÃO DA UNIVERSIDADE DE COIMBRA 


\title{
Segurar a família pelas pontas: Os dilemas dos avós cuidadores a tempo inteiro
}

\author{
Helena Jorge ${ }^{1}$ e Wolfgang Lind $^{2}$
}

Holding family by the ends: Grandparents' dilemmas as fulltime caregivers

\begin{abstract}
Caring for a grandkin on a full-time basis, when biological parents are permanently absent, is an unexpected task for grandparents. However, in contemporary society, this is an increasingly emergent problem in many countries. The increase in unemployment, divorce, emigration, teenage pregnancy, drug use, detention, terminal diseases or biological parents' death push grandparents to assume responsabilities that make them face individual, intra-familiar and extra-familiar dilemmas. Using a systemic view as a background, this article highlights particularities of this new family configuration.
\end{abstract}

Keywords: grandparents; caregivers; family relationship; grandkin; grand-parenting

1 Doutoranda do Curso Inter-Universitário de Doutoramento em Psicologia Clínica, de Psicologia da Família e Intervenção Familiar, das Universidades de Coimbra e de Lisboa. Email: helena.vmjorge@gmail.com

2 Professor auxiliar da Faculdade de Psicologia da Universidade de Lisboa. Email: mwlind@hotmail.com 


\section{Resumo}

Cuidar dos netos a tempo inteiro, na ausência permanente dos pais biológicos, é uma tarefa inesperada pelos avós. No entanto, constitui uma realidade cada vez mais emergente, em vários países do Mundo, na sociedade contemporânea. $\mathrm{O}$ aumento de fenómenos como o desemprego, o divórcio, a emigração, a gravidez na adolescência, o consumo de substâncias psicoativas, prisão, doenças terminais ou a morte dos pais biológicos empurram os avós para assumir responsabilidades que os colocam perante dilemas individuais, intrafamiliares e extrafamiliares. Usando como pano de fundo uma grelha sistémica, este artigo destaca as especificidades desta nova forma familiar.

Palavras-chave: avós; cuidadores; relações familiares; netos; grã-parentalidade

\section{INTRODUÇÃO}

Em Portugal, 70.5 \% dos avós fazem parte da rede direta de apoio parcial das famílias portuguesas, seja no suporte financeiro, seja no cuidado aos netos ou em qualquer outro tipo de apoio (Aboim, Vasconcelos \& Wall, 2013). O estudo europeu "A prestação de cuidados dos avós na Europa" revelou recentemente que mais de 40\% dos avós em 11 países europeus asseguram o cuidado aos netos, sendo que em Portugal a prestação de cuidados intensivos (diários ou mais de 15 horas por semana) é superior aos cuidados ocasionais ou menos intensivos (Glaser, Price, Montserrat, Gessa \& Tinker, 2013).

Se para estes avós, abdicar de um futuro e tempo planeados (a reforma e as atividades recreativas), reorganizar as relações com os seus familiares e com os seus pares são algumas exigências impostas, porque decidem os avós cuidadores a tempo inteiro aceitar cuidar dos netos na ausência dos pais? Que outros dilemas se colocam a estas pessoas de meia-idade e idade avançada, na esfera da sua identidade pessoal, na sua relação com os outros, na sua competência parental e na integração da história familiar com o futuro geracional?

Sendo uma problemática identificada e estudada primeiramente nos Estados Unidos da América, durante os anos 70, com aproximadamente 2.2 milhões de crianças a viver com os avós (Minkler \& Fuller-Thomson, 1999), este fenómeno cresceu 50\%, em 20 anos. No Canadá, México, Inglaterra e Austrália estima-se que mais de $5 \%$ das crianças em idade escolar estejam ao cuidado permanente dos seus avós (para um estudo mais aprofundado da realidade em Inglaterra, aconselha-se a consulta do relatório dos resultados do inquérito da Grandparents Plus, Gautier, 
Wellard, \& Cardy, 2013). No Brasil, "apesar da sua importância para a sociedade, os avós que criam seus netos ainda têm sido pouco estudados", de acordo com Dias, Costa e Rangel (2005, p. 160). O mesmo acontece em Portugal, apesar de o número de crianças entregues a outros familiares ter aumentado nos últimos anos: de 763, em 2005 para 3811, em 2012, registando-se um aumento drástico no ano de eclosão da crise económica mundial atual: entre 2008 e 2009, passou-se de 1056 para 4874 casos, segundo dados da Comissão Nacional de Crianças e Jovens em Risco.

Esta realidade tende a crescer e está associada a acontecimentos familiares e de vida negativos enquanto precedentes da formação desta nova constelação familiar. Edwards e Ray (2010) elencaram nove destas situações, que denominaram os "9 D's": divorce (divórcio), desertation (abandono), drugs (drogas), death (morte), diseases (doenças), delivery (adolescent childbirth) (gravidez na adolescência), detention (prisão), deployment (mobilidade profissional) e departure (partida emigração).

As circunstâncias relacionadas com a gravidez na adolescência, o divórcio dos pais e o desemprego estão também ligados a estudos da coparentalidade ou ao estudo dos agregados familiares multigeracionais, nos quais coabitam avós, pais e netos. Estas soluções de coabitação estão associadas à falta de independência financeira parental (Albuquerque, 2011; Pebley \& Rudklin, 1999). Aos avós em full-time, na ausência de pais biológicos, associam-se preferencialmente situações de abandono ou incapacidade parental temporária ou permanente (Alexandre, 2010; Dias, Costa \& Rangel, 2005; Malita, 2008).

Edwards \& Taub (2009) usam a expressão custodial grandparents para definir estes avós, incluindo a presença dos pais biológicos, sendo que a responsabilidade parental está imputada aos avós e pode ser exercida formal (através de suporte legal) ou informalmente (como um mero membro da família alargada com a responsabilidade de criar a criança). Já Fuller-Thomson (2005) inclui apenas os avós que vivem com os netos, sem outros familiares presentes, de forma a perceber-se clara e inequivocamente quem exerce a função parental.

Relativamente às características sociodemográficas, a literatura aponta para uma população heterogénea, com um intervalo de idades bastante alargado, com 2/3 dos avós entre os 45 e os 64 anos, em que cerca de metade destes adultos ainda estão no mercado de trabalho, e a maioria são avós cuidadoras, no feminino (Fuller-Thomson, 2005).

Estes avós defrontam-se com uma crise não normativa do sistema familiar, que acarreta várias decisões e alterações profundas para todos os envolvidos. Isto exigir-lhes-á ajustamentos ao nível individual, familiar e social. Organizado segundo três níveis de interação - dilemas individuais, dilemas intrafamiliares e dilemas 
extrafamiliares —, este artigo pretende explorar as seguintes questões: (a) Como conciliam a continuidade familiar e a independência geracional? Como se adaptam à simultaneidade de papéis - de avós e das responsabilidades parentais?; (b) Que opções tomam no âmbito familiar, na relação com os filhos biológicos, apoiam-nos ou desistem? Que inquietações surgem pela inversão nos cuidados familiares, no que se refere à autonomia dos netos e à possível dependência progressiva dos avós?; (c) Que transformações ocorrem na sua rede social e que barreiras e facilitadores encontram perante a educação num "mundo diferente", a escola e a sociedade?

\section{DILEMAS INDIVIDUAIS}

\section{Continuidade familiar versus Independência geracional}

Perante a decisão de aceitar a custódia dos netos, os avós ficam expostos a um conflito entre a continuidade familiar e a independência geracional, descrito por Climo, Terry e Lay (2002) como um double bind: se por um lado, aceitar cuidar do neto significa cumprir um dever familiar de coesão, unidade e proteção, por outro lado, confirmam a impossibilidade de os filhos exercerem a sua função parental, bloqueando a função externa da família. Apesar deste impasse na comunicação intergeracional, a maioria dos estudos revela que estes avós optam por assumir o lugar dos filhos. No fundo, parece que respondem ao seu duplo papel: pais dos filhos adultos, ajudando-os num momento difícil, e avós dos netos, mantendo-os na família (Bailey, Letiecq \& Porterfield, 2009; Climo, Terry \& Lay, 2002; Edwards \& Ray, 2010).

As razões que apresentam para esta decisão são múltiplas: contribuir para um sentimento de continuidade familiar, manter a criança longe das instituições de proteção de crianças e jovens, não haver outro familiar disponível para aceitar este cargo, manter a segurança da criança e proporcionar-lhe um espaço de pertença familiar, ter uma segunda oportunidade para ser pais, por obrigação, dever ou lealdade familiar, por amor ou, finalmente, por influência espiritual ou religiosa (Hayslip \& Kaminski, 2005).

No entanto, quer o padrão de corresidência, tendencialmente crescente em Portugal (Albuquerque, 2011), quer a noção de família nuclear de outras culturas, que inclui todos os familiares próximos e distantes (Kuyini, Alhassan, Tollerud, Weld \& Haruna, 2009) atenuam este dilema e trazem um enquadramento que valoriza o apoio mútuo entre várias gerações. Edwards e Ray (2010) acrescentam que, nas 
famílias em geral, os avós que esperam ajudar os pais a criar os netos evidenciam menores níveis de stress do que aqueles que não contemplam este apoio no seu projeto de vida. Apesar destes facilitadores, estes resultados deixam antever outros dilemas individuais, como a coexistência de papéis - avós e pais - cuja resolução parece passar pela construção de um novo papel.

\section{Simultaneidade versus Diferenciação de papéis (Pais e Avós)}

Sequências normativas do ciclo vital da família (Relvas, 2000) são inesperadamente alteradas quando, após o ninho vazio, os avós tornam a ser cuidadores a tempo inteiro dos seus netos. (Bailey, Letiecq \& Porterfield, 2009). Como lidam estes avós com estas transições? O que sentem? Abdicam do papel tradicional de avós e tornam-se novamente pais? Ou não se permitem ser pais e assumem-se como avós? Ou, pelo contrário, será um caminho de aprendizagem de um novo papel na transição entre um e outro?

Do ponto de vista da função educadora da família (Barros de Oliveira, 2009), aos avós e aos pais têm sido tradicionalmente atribuídos papéis e estatutos distintos, independentemente das evoluções e mutações familiares. Cruz (2005) sintetiza as cinco funções da parentalidade apresentadas por vários autores como Bernstein, em 2002, Palácios e Rodrigo, em 1998, e Parke e Buriel, em 1998:

satisfazer as necessidades básicas dos filhos; disponibilizar à criança um mundo físico e organizado; responder às necessidades da compreensão cognitiva das realidades extrafamiliares; satisfazer as necessidades de afeto, confiança e segurança; e necessidade de interação social da criança e sua integração na comunidade. (p.14)

Respondem, por isso, ao compromisso entre a função interna (proteção) e a função externa (socialização) da família. Os pais desempenhariam, pois, papéis de parceiros de interação, ao nível dos afetos, da disciplina e das rotinas, instrutores diretos na resolução de problemas e guias do caminho para aprendizagem em contextos extrafamiliares, conforme estipula o modelo tripartido de Parke e Buriel (Cruz, 2005, p.15).

Já para os avós, de acordo com Kivnick (1982), as funções concentrar-se-iam em assegurar a continuidade e os laços de filiação, transmitir conhecimentos, funcionar como fonte de sabedoria, acarinhar a criança e promover o seu desenvolvimento, aproveitando o tempo para realizar tarefas de que eles gostam, guardar a memória familiar, favorecendo a transmissão das tradições e valores familiares, educativas e culturais e reviver experiências educativas anteriores. 
Os avós de Hoje, pilares de suporte emocional e instrumental, desdobram-se em múltiplas tarefas. Recorrendo à literatura psicanalítica, tornar-se avós corresponde à quarta individuação nos vários processos de sucessivas separações (Colarrusso, 1997). Os avós experienciam renovação, preenchimento de um vazio após a saída dos filhos de casa, o concretizar de uma expectativa e uma oportunidade de refletir sobre a sua vida, sobre os seus papéis e as suas relações. Segundo o mesmo autor, a autonomia dos filhos estimula a independência dos pais, corroborando o ditado popular "quem os fez que os crie". Esta é também uma frase que Relvas e Lourenço (2001, p. 126) utilizam para exemplificar como os avós "não querem de novo perder a liberdade ganha a partir do momento em que, junto dos próprios filhos, puderam sentir o alívio do peso da parentalidade". E é nesta relação descomprometida que cresce uma relação de cumplicidade, que alimenta os mitos expressos em provérbios como "os pais educam e os avós deseducam" e que confere satisfação recíproca.

Para os avós cuidadores a tempo inteiro, na ausência dos pais biológicos, a grã-parentalidade e a parentalidade surgem em simultâneo. A relação com os netos não é desprovida de responsabilidades parentais diretas. Esta ambiguidade de papéis parece traduzir-se pela voz dos netos. Bailey, Letiecq e Porterfield (2009) referem que os netos nomeiam as avós de diferentes formas (umas vezes por avó, outras vezes por mãe e, outras vezes, pelo nome próprio). No mesmo estudo, foi possível observar que os netos mais velhos conseguem distinguir melhor os papéis de pais e avós.

Quando os filhos destes avós são considerados temporariamente inaptos como pais, os avós experienciam também sentimentos de culpa e ressentimento associados à perceção de não terem sido competentes como pais, colocando em dúvida a sua capacidade para assumir esta tarefa.

Num estudo realizado por Hayslip, Shore, Henderson e Lambert (1998), que pretendia analisar o grau de satisfação destes avós com o desempenho do seu novo papel parental, encontraram-se diferenças estatisticamente significativas entre os avós tradicionais e os avós a tempo inteiro, cujos netos tinham muitos problemas de comportamento, existindo um impacto negativo superior para os segundos. De destacar também que este impacto não é reduzido por outras variáveis como duração da relação enquanto avós tradicionais e avós a tempo inteiro, número de netos, idade dos avós e autoperceção da sua saúde.

Desfazendo as dúvidas quanto à diferença nas atitudes educativas parentais, Kaminski, Hayslip, Wilson e Casto (2008) não encontraram diferenças entre estes avós e os pais biológicos quando se trata de educar uma criança com problemas de comportamento. Quanto às crenças relativas à punição corporal ou outra medida de ajustamento parental, enquanto prática educativa, o grupo de avós cuidadores a tempo inteiro não diferiu do grupo de pais e do grupo de avós tradicionais. 
Mas será que a perceção da experiência prévia de parentalidade é um fator preponderante neste dilema da simultaneidade de papéis? Mais uma vez no feminino, indiciando a escassez de estudos com avôs, Dolbin-MacNab (2006) descobriu que as avós cuidadoras a tempo inteiro que percecionavam mais diferenças entre criar um neto e criar um filho e que imputavam essas diferenças a fatores positivos (mais experiência, mais tempo e atenção para cuidar e menos pressão relativa ao cumprimento de expectativas relacionadas com este papel), mostravam ter resolvido melhor os sentimentos de ambivalência. Pelo contrário, aquelas que percecionavam mais diferenças, mas as associavam a fatores negativos (falta de energia, limitações físicas, idade não normativa, vontade de aproveitar a reforma) referiam mais dificuldade em aplicar uma disciplina efetiva, com fortes sentimentos de ambivalência relacionados com a qualidade da parentalidade e a relação com os netos. Por fim, quanto às avós cuidadoras a tempo inteiro que percecionavam mais semelhanças do que diferenças (repetição de estratégias parentais ou igual intensidade na relação com os netos) pareciam sentir-se mais confiantes no desempenho do seu papel.

Algumas questões permanecem, ainda, em aberto. Será que estas avós se identificavam fortemente com este papel ou será que nunca deixaram, realmente, de o exercer? Ou ainda, será que se tratava de uma forma de posse dos netos para resolver a ambiguidade de papéis ou sentimentos ambivalentes? Ausloos (2003) definindo codependência (um processo patogénico familiar), alerta que:

quando se segue uma regra durante uma boa parte da vida, é pouco provável que esta regra se modifique ao envelhecer. (...) O pior pode advir do facto de eles não terem suportado as veleidades de independência do seus filhos, e que tentem compensá-las ligando-se aos seus netos numa dependência ainda mais forte. (pp. 143-144)

Para muitos destes avós, esta é uma segunda oportunidade para serem pais, para serem melhores pais. Permitem-se criar um novo papel, diferente do anterior, construindo um novo significado, uma nova identidade enquanto avós, aliados a outros fatores contextuais, como a reforma ou a idade. Se alguns pais referem que só se sentem verdadeiramente a atuar como pais quando começam, de alguma maneira, a ter de restringir e controlar o comportamento dos filhos (Cruz, 2005), em que medida as práticas educativas destes avós facilitarão o desfecho desta encruzilhada? Sendo a parentalidade a responsabilidade central destes avós, é de esperar que os restantes dilemas ao nível intrafamiliar e extrafamiliar estejam com ela relacionados. 


\section{DILEMAS INTRAFAMILIARES}

\section{Conciliar gerações versus Abortar gerações}

Como em qualquer outra mutação familiar, as relações dentro da família necessitam de ser repensadas e renegociadas. Começando pelos próprios filhos e excluindo situações de perda dos pais por morte ou emigração, colocam-se novas interrogações. Em que medida o contacto entre pais e filhos é desejado, tendo em conta as circunstâncias que poderão ter originado esta situação? O que fazer e dizer se a criança ou o jovem não deseja ver os pais ou, pelo contrário, não quer ou não legitima os avós como seus cuidadores principais? E os outros filhos e netos, o que fazer e dizer quando reclamam a disponibilidade ou não aceitam a decisão dos pais/avós em tomar conta dos filhos dos seus irmãos/tios?

É curioso constatar que, por vezes, estes avós se referem aos seus filhos "incapacitados" como "o pai" ou "a mãe" do meu neto, utilizando a expressão de "filho(a)" quando querem nomear os outros filhos. Esta distância emocional, descrita por Wohl, Lahner e Jooste (2003), parece traduzir vários sentimentos, sintetizados pelo mesmo autor: vergonha e culpa, por terem criado pais considerados irresponsáveis; raiva, por lhes ter alterado o curso de vida normativo; medo, pelo poder que sentem que este filho detém sobre eles.

Se há pais biológicos que consentiram esta "entrega" dos filhos, outros há que não concordaram e, portanto, os conflitos anteriores e os desentendimentos atuais agudizam-se. A luta pela custódia das crianças, a ameaça do reaparecimento dos pais ou a possível desorganização da vida dos netos podem estar constantemente latentes na vida destes avós. Como forma de responder a este medo legítimo, estes novos cuidadores a tempo inteiro podem ser compelidos a sobreproteger estes netos e a afastarem-se dos seus próprios filhos adultos (Bailey, Letiecq e Porterfield, 2009). Esta decisão de conciliar ou abortar uma geração passa igualmente pela relação com os outros filhos, que por diversas perceções das suas relações intrafamiliares passadas poderão entender a ajuda aos sobrinhos (filhos destes irmãos) com ressentimento, ciúmes e oposição. Esta ausência de compreensão do papel destes avós pode levar ao afastamento dos outros filhos e, consequentemente, dos netos que não estão ao cuidado destes avós, como forma de protesto pelo apoio a um(a) outro(a) irmão(ã) ou primo(a).

Este dilema é idêntico a um processo de luto não reconhecido ou desconhecido pelos outros, tendo estes avós que lidar com as perdas secundárias da ausência 
física, emocional ou mesmo morte do filho biológico, bem como lidar com uma criança (neto/a) igualmente em luto pela perda dos seus pais.

\section{Dependência dupla versus Dependência à vez: cuidar e ser cuidado}

De acordo com o modelo de solidariedade intergeracional de Bengston, de 1985, existem seis dimensões de solidariedade para avaliar o nível de coesão social entre as gerações: os sentimentos que os membros da família expressam acerca das relações com outros membros da família (afetiva), o tipo e frequência de contacto entre elementos de diferentes gerações (associativa), o acordo entre opiniões e valores entre gerações (consensual), o dar e receber suporte entre gerações (funcional), as obrigações filiais e parentais esperadas (normativa) e, por último, a proximidade geográfica entre os membros de diferentes gerações (estrutural).

À luz deste modelo e perante duas gerações que, à partida, têm probabilidade de vir a necessitar de cuidados e coabitam sem o apoio da geração intermédia, o contrato geracional dentro das famílias é parcialmente quebrado em várias dimensões (Bengston \& Oyama, 2007). Por exemplo, ao nível das solidariedades normativa e funcional, os avós esperariam ser cuidados pelos filhos ou pelos netos e não perpetuar um cuidado às gerações mais novas. No entanto, Wohl, Lahner e Jooste (2003) constataram que nas famílias de muitos avós cuidadores a tempo inteiro que participavam nos seus grupos de suporte existia um padrão familiar intergeracional de cuidados. Isto é, os filhos destes avós já tinham sido criados pelos seus próprios avós. Os autores passaram, então, a usar uma perspetiva sistémica familiar, com a utilização do genograma como instrumento de intervenção.

Esta inversão nos cuidados familiares trará novas inquietações. Por um lado, os avós preocupam-se se viverão o suficiente para criar os netos. Por outro lado, se terão alguém que cuide deles na sua aproximação à morte. Uma das consequências da vontade de deixar os netos criados pode ser, por exemplo, a aceleração de projetos de vida profissionais que autonomizem financeiramente o neto (Dolbin-MacNab \& Targ, 2003). Se houver acordo mútuo, a escolha de cursos profissionais e a saída da escola mais precocemente poderão ocorrer com mais probabilidade. Do ponto de vista das crianças, a não motivação para estudar e o insucesso escolar poderão ser uma solução de compromisso para responder à vontade de crescer como as outras crianças e ao mesmo tempo não desiludir os avós com uma não-escolha.

Outra consequência da dependência dupla é a parentificação deste neto, podendo este ter de resolver problemas relacionados com as tarefas domésticas ou cuidados de saúde, caso estes avós estejam temporariamente debilitados ou se tiverem de se ausentar para trabalhar. Talvez seja nos netos que estes avós, consciente ou incons- 
cientemente, depositam a sua esperança nos cuidados à velhice. Numa perspetiva de solidariedade intergeracional preconizada nas famílias, um estudo de Wolf, realizado no final da década de 80 , concluiu que os netos cujos avós cuidaram deles manterão com estes uma relação privilegiada (Ramos, 2005). Outros fatores como a coabitação de longa data (solidariedade associativa) e a proximidade geográfica (solidariedade estrutural) poderão facilitar esta prestação de cuidados. No entanto, faltam estudos longitudinais sobre as implicações no idoso e, mais tarde, no neto adulto, acerca destes cuidados prestados anteriormente pelos avós durante a infância e a adolescência.

\section{DILEMAS EXTRAFAMILIARES}

Do apoio percebido aos ajustes nas redes de suporte informal e formal do cuidador

O apoio percebido está associado a melhores níveis de saúde do cuidador, bem como a melhor capacidade para se adaptar às solicitações da parentalidade (Hayslip \& Kaminski, 2005). Num estudo de Sands e Goldberg-Glen (2000), a falta de recursos ou suporte explicava $10 \%$ da variância do stress destes avós. Daí que a qualidade de vida destes avós venha sendo alvo de alguns estudos.

Quando os avós cuidadores a tempo inteiro assumem as responsabilidades parentais, a sua rede de suporte informal altera-se, passando a dispor de menor tempo para conviver com os seus pares: sentem-se sozinhos, diferentes e têm um sentimento de invisibilidade (Wohl, Lahner \& Jooste, 2003). Esta situação pode conduzir ao isolamento social e, consequentemente, colocá-los perante o risco de problemas acrescidos de saúde mental e física. Num estudo de Lee, Colditz, Berkmam e Kawachi (2003, citado em Hayslip \& Kaminski, 2005), o risco de doença coronária aumentava nas avós que estivessem a cuidar diariamente dos netos a partir de 9 horas por dia. Os avós cuidadores a tempo inteiro têm também uma dupla probabilidade de desenvolver depressão (Minkler \& Fuller-Thomson, 1999).

No caso de um casal de avós cuidadores, a avaliação do nível de exaustão do cuidador deverá ainda ter em conta outras variáveis como a qualidade da relação conjugal, a permanência no mercado de trabalho e a sintomatologia das crianças ao seu cuidado. Em parte devido aos acontecimentos familiares precedentes, estas crianças podem manifestar mais dificuldades em estabelecer relações de confiança com os pares e com os adultos. Um estudo de Solomon e Marx, realizado em 1995 
(cf. Edwards, 2006), demonstra que estas crianças em idade escolar apresentam mais dificuldades académicas do que as que vivem com ambos os pais ou aquelas que vivem apenas com uma figura parental. No entanto, na mesma amostra, não foram encontrados dados que indiquem diferenças no ajustamento socioemocional e comportamental. Outros estudos há, porém, que evidenciam que tanto os avós como os professores identificam mais problemas de externalização e de internalização nestas crianças do que nos seus pares (Edwards, 2006).

Esta sintomatologia pode, paradoxalmente, abrir a rede de suporte instrumental na área da saúde, quer para a criança, quer para o adulto, mas diminui, mais uma vez, o tempo de lazer de ambos e altera as rotinas familiares que girarão em torno das consultas e dos apoios socioeconómicos (formais), nomeadamente no caso das famílias com baixos rendimentos.

\section{Educar hoje com os valores de ontem - escola e sociedade}

É também na escola e na sociedade que os avós a tempo inteiro se debatem com outro dilema: como educar Hoje?

Uma das razões, apresentadas por 35\% dos avós entrevistados no estudo de Dolbin-MacNab (2006) para a dificuldade de educar os netos, em comparação com os seus filhos, estava relacionada com a educação "num mundo diferente". As atitudes liberais perante a sexualidade, crime, violência, drogas, álcool, os computadores, os jogos e os meios de comunicação social são vistos como barreiras a uma educação bem-sucedida dos netos. Estes avós têm necessidade de informações acerca de "educar na sociedade contemporânea" à semelhança dos pais.

Curiosamente, os confrontos acerca das ideias educativas estão muito ligados às questões da disciplina e da manifestação da autoridade. No estudo de Kaminski e Hayslip, de 2004 (Hayslip \& Kaminski, 2005), os avós cuidadores a tempo inteiro tinham tendência a ser menos responsivos às necessidades psicoemocionais das crianças, a valorizar mais a obediência e a perceber a diferença de opiniões como um sinal de desrespeito. Deste ponto de vista, parecem aproximar-se dos avós não cuidadores. Segundo Relvas (2000, p. 213), “os modelos de rigidez educativa utilizados com os filhos só ligeiramente se esbatem na relação com os netos”. A diferença crucial entre avós cuidadores a tempo inteiro e não cuidadores é que os primeiros têm de atuar e os segundos deverão articular os seus modelos de parentalidade sem interferência e estão inseridos numa vivência da relação com os netos diferente e menos ambivalente.

Para além da temática do conflito de gerações e da relação escola-família habitual nas fases do ciclo vital da família com filhos (pequenos e adolescen- 
tes), o tempo histórico determina, então, a diferença na hierarquia dos valores. Este cruzamento sociológico atribui aos dilemas extrafamiliares uma dimensão macrossistémica.

\section{MODELOS E PROGRAMAS DE INTERVENÇÃO}

Em vários países, têm sido pensados modelos e programas de intervenção específicos para estas famílias. Brown-Standridge e Floyd (2000) sugerem uma adaptação da Contextual Family Therapy e Dolbin-MacNab e Targ (2003) avançam com linhas orientadoras para os profissionais que trabalham com estas famílias.

Nos Estados Unidos da América, existem mesmo associações que propõem programas de formação e apoio para estes avós, como a "Grandparents Raising Grandchildren” ou a "Grandparents as Parents". No Canadá, existem estruturas residenciais que se destinam a estes agregados familiares, chamadas de "Grand-Families Houses", uma vez que os lares convencionais não aceitam crianças. Na Austrália, está em curso um programa de educação parental denominado "Triple P for Grandparents", a cargo de Mattew Sanders.

Para os avós, destacamos dois modelos concetuais que orientam a intervenção:

Um primeiro modelo, o modelo concetual de Stress e Coping de Crowther e Rodriguez (2003), que preconiza a coexistência de quatro componentes. Em primeiro lugar, o contexto. Em segundo lugar, as razões precipitantes (stressor primário). Em terceiro lugar, a discrepância entre a situação atual e a que seria esperada (stressor secundário). Estes três componentes explicariam a qualidade de bem-estar e saúde destes avós, a qual seria mediada e moderada pelo quarto componente: os processos de adaptação - satisfação com o papel familiar, suporte social e coping.

Em segundo lugar, destaca-se o modelo integrativo de avaliação de Conway e Stricker (2003), focado nos recursos e não nos problemas, permitindo uma avaliação estruturada, mas flexível, para integrar a experiência única de cada avô. É baseado no modelo de desenvolvimento de Erickson, nos estudos da vinculação e na Teoria Ecológica dos Sistemas de Bronfenbrenner. Este modelo descreve esquematicamente oito componentes que incidem em oito objetivos precisos: (1) experiências que contribuíram para desempenhar a função parental como avô; (2) conjunto de dificuldades e recursos resultantes do papel de cuidador; (3) avaliação das tarefas e expectativas desenvolvimentais dos avós, dos pais e das crianças (4) qualidade das relações diádicas e triádicas, áreas de conflito e áreas de acordo (5) pesquisa da qualidade de relações no microsistema, que permite inferir acerca da rede de apoio; (6) mesossistema, em especial a relação com a escola e os serviços de saúde; 
(7) exossistema e (8) integração da informação recolhida, permitindo a identificação de pontos de intervenção.

Segundo os autores, estas intervenções poderão seguir dois caminhos: (a) reforçar os recursos do sistema, nomeadamente através de: (i) presença de áreas livres de conflito na interação da tríade; (ii) microssitemas partilhados que sejam representativos de interações de respeito e apoio; (iii) relações recíprocas positivas de cuidado; (iv) procedimentos e políticas do exossistema que apoiem a situação destes avós (b) focar as áreas vulneráveis de cuidado, nomeadamente: (i) presença de interações conflituosas na tríade; (ii) interações prejudiciais na díade; (iii) microssistemas partilhados que sejam negativos e pouco apoiantes; (iv) procedimentos e políticas do exossistema que colidam com a capacidade dos avós exercerem a sua função cuidadora dos netos.

Para as crianças, destaca-se o modelo conceptual de promoção positiva do desenvolvimento, definido por Edwards e Taub (2009) que tem como objetivo maximizar trajetórias de desenvolvimento saudáveis, baseado num novo paradigma - o desenvolvimento positivo da criança (PYD - Positive Young Development) que alia os recursos aos suportes ecológicos. Inscreve-se num modelo concêntrico, no qual a criança está no centro (as suas características e o contexto envolventes) e os círculos representam as relações interpessoais (os avós, os professores, amigos, educadores e membros da comunidade), que irão determinar a capacidade da criança desenvolver os cinco fatores de desenvolvimento positivo (Competência, Autoconfiança, Caráter, Ligação aos outros e Empatia).

Quer no terreno clínico, quer no terreno educativo, as práticas profissionais parecem ter de responder a movimentos individuais e relacionais, intra e extrafamiliares, sem esquecer que os pais biológicos, mesmo que fisicamente ausentes, triangulam com a díade avós-netos (Burnette, 1999).

\section{CONCLUSÃO}

Transferir simplesmente as crianças da casa dos pais biológicos para casa dos avós não remove as circunstâncias precipitantes desta nova constelação familiar, não reduz as memórias e as separações daí provenientes, nem dá soluções para as dificuldades sentidas nos novos ajustamentos individuais e relacionais.

De um ponto de vista do exossistema, parece ser necessário estimular as intervenções microssistémicas, criando serviços inovadores e desenvolvendo políticas "padrão que liga" que deem resposta às necessidades específicas desta população, ao nível da família, das instituições de saúde e das instituiçõos educativas e, ainda, 
dos serviços sociais e judiciais, com intervenientes informados e sensíveis às problemáticas peculiares e desafiantes destes agregados.

Ao nível da investigação científica, ainda há muito trabalho a desenvolver. Se os custos e benefícios para os avós e para as crianças têm sido mais estudados, já as questões relacionadas com as atitudes e práticas parentais necessitam de uma atenção mais cuidada. A parentalidade, enquanto variável orientadora das questões educativas, familiares e médico-sociais, tem implicações quer no desenvolvimento infantil e na promoção e proteção de menores, quer no processo de envelhecimento. Estes vários aspetos devem ser tidos em conta no desenho de programas educativos grã-parentais. Os estudos existentes incidem sobre amostras nas quais prevalece, maioritariamente, o género feminino (as avós) sendo necessários estudos com o género masculino ou que incidam sobre as razões precipitantes ou a cultura/etnia. Por último, são também necessários estudos longitudinais que ajudem a perceber e a comparar esta medida de apoio junto de outro familiar, com outras medidas de promoção e proteção, como a adoção ou o acolhimento em instituição.

Ao nível da prática terapêutica, algumas das tarefas principais na intervenção com estas famílias parecem passar por intervenções multifocais que sejam sensíveis às singularidades destes agregados, com incidência particular na parentalidade. Dando respostas aos dilemas apresentados neste artigo, olhando para a experiência pessoal e intransmissível de cada família, este poderá ser um instrumento de suporte à avaliação sistémica, capaz de abarcar a complexidade destes sistemas formados "fora de tempo" e reforçar a esperança já iniciada pelos avós cuidadores a tempo inteiro: "segurar a família pelas pontas"!

\section{REFERÊNCIAS}

Aboim, S., Vasconcelos, P., \& Wall, K. (2013). Support, social networks and the family in Portugal: Two decades of research. International Review of Sociology, 23(1), 47-67.

Albuquerque, P. (2011). Grandparents in multigenerational households: The case of Portugal. European Journal of Ageing, 8(3), 189-198.

Alexandre, M. (2010). Outra vez pais: Quando os avós têm de assumir funções parentais. Revista Mosaico, 45, 35-43.

Ausloos, G. (2003). A competência das famílias ( $2^{\text {nd }}$ ed.). Lisboa: Climepsi Editores.

Bailey, S., Letiecq, B., \& Porterfield, F. (2009). Family coping and adaptation among grandparents rearing grandchildren. Journal of Intergenerational Relationships, 7, 144-158.

Barros de Oliveira, J. (2009). Psicologia da educação: Temas complementares. Porto: LivPsic.

Bengston, V., \& Oyama, P. (2007). Intergenerational solidarity: Strengthening economic and social ties. Department of Economic and Social Affairs: Division of Social Policy and Development. 
Expert Group Meeting. Consultado em http://www.un.org/esa/socdev/unyin/documents/ egm_unhq_oct07_bengtson.pdf

Brown-Standridge, M., \& Floyd, C. (2000). Healing bittersweet legacies: Revisiting contextual family therapy for grandparents raising grandchildren in crisis. Journal of Marital and Family Therapy, 26(2), 185-197.

Burnette, D. (1999). Social relationships of latino grandparent caregivers: A role theory perspective. The Gerontologist, 39(1), 49-58.

Climo, J., Terry, P., \& Lay, K. (2002). Using the double bind to interpret the experience of custodial grandparents. Journal of Aging Studies, 16(1), 19-35.

Colarrusso, C. (1997). Separation-individuation process in middle adulthood: The fourth individuation. In S. Akhtar \& S. Kramer (Eds.), The seasons of life: Separation-individuation perspectives (pp. 73-94). Northvale: Jason Aronson.

Conway, F., \& Stricker, G. (2003). An integrative assessment model as a means of intervention with the grandparent caregiver. In B. Hayslip \& J. Patrick (Eds.), Working with custodial grandparents (pp. 45-57). New York: Springer Publishing Company.

Crowther, M., \& Rodriguez, R. (2003). A stress and coping model of custodial grandparenting among african americans. In B. Hayslip \& J. Patrick (Eds.), Working with custodial grandparents (pp. 145-162). New York: Springer Publishing Company.

Cruz, O. (2005). Parentalidade. Coimbra: Quarteto.

Dias, C., Costa, J., \& Rangel, V. (2005). Avós que criam seus netos: Circunstâncias e consequências. In T. Féres-Carneiro (Eds.), Família e casal: Efeitos da contemporaneidade (pp. 158-176). Rio de Janeiro: PUC-Rio.

Dolbin-MacNab, M. (2006). Just like raising your own? Grandmother's perceptions of parenting a second time around. Family Relations, 55(5), 564-575.

Dolbin-MacNab, M., \& Targ, D. (2003). Grandparents raising grandchildren: Guidelines for family life educators and other family professionals. In B. Hayslip \& J. Patrick (Eds.), Working with custodial grandparents (pp. 213-228). New York: Springer Publishing Company.

Edwards, O. (2006). Teachers' perceptions of the emotional and behavioral functioning of children raised by grandparents. Psychology in the Schools, 43(5), 565-572.

Edwards, O., \& Ray, S. (2010). Value of family and group counselling models where grandparents function as parents to their grandchildren. International Journal of Advanced Counselling, 32, 179-190.

Edwards, O., \& Taub, G. (2009). A conceptual pathways model to promote positive youth development in children raised by their grandparents. School Psychology Quarterly, 24(3), 160-172.

Fuller-Thomson, E. (2005). Grandparents raising grandchildren in Canada: A profile of skipped generation families. Canada: SEDAP.

Gautier, A., Wellard, S., \& Cardy, S. (2013). Forgotten children: Children growing up in kinship care. Consultado em http://www.grandparentsplus.org.uk/wp-content/uploads/2011/03/ForgottenChildren-0613-4.pdf

Glaser, K., Price, D., Montserrat, E., Gessa, G., \& Tinker, A. (2013). A prestação de cuidados pelos avós na Europa: As políticas familiares e o papel dos avós na prestação de cuidados infantis. Consultado em http://www.gulbenkian.pt/mediaRep/gulbenkian/files/institucional/fundacao/ programas/PG\%20Desenvolvimento\%20Humano/pdf/A_presta____o_de_cuidados_pelos_ av__s_na_Europa.pdf

Hayslip, B., \& Kaminski, P. (2005). Grandparents raising their grandchildren: A review of literature and suggestions for practice. The Gerontologist, 45(2), 262-269. 
Hayslip, B., Shore, R., Henderson, C., \& Lambert, P. (1998). Custodial grandparenting and the impact of grandchildren with problems on role satisfaction and role meaning. The Journals of Gerontology, 53(3), 164-173.

Kaminski, P., Hayslip, B., Wilson, J., \& Casto, L. (2008). Parenting attitudes and adjustments among custodial grandparents. Journal of Intergenerational Relationships, 6(3), 263-284.

Kivnick, H. (1982). Grandparenthood: An overview of meaning and mental health. Geronthologist, 22(1), 59-66.

Kuyini, A., Alhassan, A., Tollerud, I., Weld, H., \& Haruna, I. (2009). Traditional kinship foster care in northern Ghana: The experiences and views of children, carers and adults in Tamale. Child \& Family Social Work, 14, 440-449.

Malita, E. (2008). Involving caregiving grandmothers in family interventions when mothers with substance use problems are incarcerated. Family Process, 47(3), 357-371.

Minkler, M., \& Fuller-Thomson, E. (1999). The health of grandparents raising grandchildren: Results of a national study. American Journal of Public Health, 89, 1384-1389.

Pebley, A., \& Rudkin, L. (1999). Grandparents raising grandchildren: What we know? Journal of Family Issues, 20, 218-221.

Ramos, N. (2005). Relações e solidariedades intergeracionais na família: Dos avós aos netos. Revista Portuguesa de Pedagogia, 39(1), 195-216.

Relvas, A. (2000). O ciclo vital da família. Santa Maria da Feira: Edições Afrontamento.

Relvas, A., \& Lourenço, M. (2001). Uma abordagem familiar da gravidez e da maternidade. Perspectiva sistémica. In M. C. Canavarro (Ed.), Psicologia da gravidez e da maternidade (pp. 105-132). Coimbra: Quarteto.

Sands, R., \& Goldberg-Glen, R. (2000). Factors associated with stress among grandparents raising their grandchildren. Family Relations, 49(1), 97-105.

Wohl, E., Lahner, J., \& Jooste, J. (2003). Group processes among grandparents raising grandchildren. In B. Hayslip \& J. Patrick (Eds.), Working with custodial grandparents (pp. 195-211). New York: Springer Publishing Company. 